\title{
Effect of Rolling in the Recrystallization Temperature Region Associated with a Post-Heat Treatment on the Microstructure, Crystal Orientation, and Mechanical Properties of API 5L X70 Pipeline Steel
}

\author{
Mohammad Masoumi ${ }^{a *}$, Cleiton Carvalho Silva ${ }^{a}$, Hamilton Ferreira Gomes de Abreu ${ }^{a}$ \\ ${ }^{a}$ Department of Metallurgical and Materials Engineering, Federal University of Ceará - UFC, Campus \\ do Pici, Bloco 729 CEP 60.440-554, Fortaleza, CE, Brazil
}

Received: September 9, 2016; Accepted: November 21, 2016

\begin{abstract}
In order to improve the mechanical properties of API X70 pipeline steel, a rolling schedule in the recrystallization temperature region associated with a post heat treatment was proposed. Optical and scanning electron microscopy, electron backscattered diffraction, hardness, and tensile tests were carried out to show the effects of microstructure and crystallographic orientation on the final mechanical properties. The normalized hot-rolled sample and the sample subjected to hot-rolling followed by quenching and consequent tempering at $700{ }^{\circ} \mathrm{C}$ exhibited an excellent combination of yield strength and elongation. This was attributed to the recrystallized ferrite microstructure and tempered martensite with martensite-austenite constituent dispersion, respectively. In addition, the development of (112)[111] and (111) $[10 \overline{1}]$ texture components and the high fraction of low angle boundaries have a significant effect on the improvement of the mechanical properties.
\end{abstract}

Keywords: API $5 L X 70$, recrystallization temperature, crystallographic orientation, mechanical properties

\section{Introduction}

American Petroleum Institute (API) pipeline steels are kinds of microalloyed steels that are used more and more all over the world. These steels offer excellent mechanical properties, the highest safety in pipeline operation, and low $\operatorname{costs}^{1-3}$. Thermomechanical control processing (TMCP) is used industrially to produce high-strength low-alloy (HSLA) steels. It refers to a continuous deformation schedule above and below the recrystallization temperature, followed by accelerated cooling, to attain a fine and uniform acicular ferrite microstructure. Although the TMCP process leads to an excellent combination of strength and ductility, it also has some disadvantages. The reduction of the rolling temperature increases the rolling loads and many mills are not designed to resist the additional stresses. Besides, waiting time is usually incorporated in the rolling schedule, and precise temperature control can increase the rolling time and reduce productivity, leading to increased manufacturing costs. Therefore, in this work a rolling procedure based on engineering of the crystallographic texture in the recrystallization temperature region of the austenite phase associated with a post heat treatment was suggested. In this regard, hot rolling produces a new set of strain-free grains that are replaced during recrystallization of austenite grains followed by ferrite transformation.

It is well-known that the crystallographic texture developed during the manufacturing process plays a significant role in the mechanical properties ${ }^{4-6}$. The texture of a rolled sheet is

* e-mail: mohammad@alu.ufc.br represented by $\{\mathrm{hkl}\}<\mathrm{uvw}>$, which means that $\{\mathrm{hkl}\}$ planes are parallel to the rolling plane and the $<\mathrm{uvw}>$ directions are parallel to the rolling direction ${ }^{7}$. Masoumi et al. ${ }^{8}$ reported that the $\{110\} / \mathrm{ND}$ (normal direction) and $\{111\} / \mathrm{ND}(\gamma$-fiber) texture components, which are developed by shear deformation close to the surface layers due to the friction between the mill and surface sheet, can improve the mechanical properties. Blonde et al. ${ }^{9}$ showed that the grains associated with $\{100\}$ planes are the most strained by the applied stress in comparison to the strain development for other grain orientations. Nafisi et al. ${ }^{10}$ and Yang et al. ${ }^{11}$ also studied the effect of texture evolution on the mechanical properties of API X100 steel. They concluded that the $(001)<110>$ rotated cube components provide cleavage planes that facilitate crack nucleation and propagation. In contrast, $\gamma$-fiber, $\{110\} / / \mathrm{ND},(332)<113>$, and $(112)<110>$ components provide good yield and ultimate tensile strengths because they provide enough slip systems during deformation. Moreover, Xie et al. ${ }^{12}$ and Yang et al. ${ }^{13}$ found that the low angle boundaries (LABs) and coincidence site lattice boundaries (CSL) are crack resistant, due to good lattice compliance. Meanwhile, the high angle boundaries (HABs) with higher stored energy due to higher lattice distortion are prone to crack nucleation and propagation.

The aim of this work was to engineer the microstructure and crystallographic texture by applying a new rolling procedure in the recrystallization temperature region associated with a post heat treatment such as normalizing, quenching, and tempering to obtain acceptable mechanical properties according to the API 5L specifications ${ }^{14}$. 


\section{Experimental methods and procedures}

An API 5L X70 steel (0.099 C-1.664 Mn-0.04 Al-0.02 Ti-0.258 Si (wt.\%)) with a thickness of $8 \mathrm{~mm}$ was used in this study. The as-received steel plate had banded ferritepearlite with a partially recrystallized microstructure with mean grain sizes of $8 \pm 1 \mu \mathrm{m}$ and dominant $\{001\} / / \mathrm{ND}$ and $\gamma$-fibres as the common texture orientation during hot rolling production (Figure 1). Precipitations and inclusions such as MnS facilitate the breakdown of bonds and create preferred sites for crack initiation, leading to early fracture. To eliminate the undesirable inclusions and develop the fully strain-free recrystallized microstructure, the plate was subjected to a solution heat treatment at about $1200^{\circ} \mathrm{C}$ for 3600 seconds. Next, the resulting plate was cut into four samples. Then, the samples were rolled by two-pass step rolling ( $8 \mathrm{~mm} \rightarrow 6 \mathrm{~mm} \rightarrow 2.6 \mathrm{~mm}$ ) in the recrystallization temperature range (recrystallization temperature calculated approximately $1006^{\circ} \mathrm{C}$ ) using a Stanat model TA-315 rolling machine with a rotational speed of $273 \mathrm{rpm}$. It is notable that the recrystallization temperature was determined by the chemical composition according to the equation proposed by Palmiere et al. ${ }^{15}$. The start and finish temperatures during the rolling operation were measured by a Minolta/Land Cyclops 152 infrared thermometer and were recorded as 1050 and $950{ }^{\circ} \mathrm{C}$, respectively. Then the rolled samples were subjected to different post heat treatments as listed in Table 1, called AC, ACN, WQ350, and WQ700, where $\mathrm{AC}$ and WQ denote air cooled and water quenched, respectively. The main purpose of performing various post heat treatments of the rolled samples was to obtain different microstructures and textures to show their effects on the mechanical properties.

For the microstructural analysis, the cross-sections (RD-ND) of specimens were ground with 120, 220, 400, 600 , and 1200-grit $\mathrm{SiC}$ papers and polished with 6,3 , and

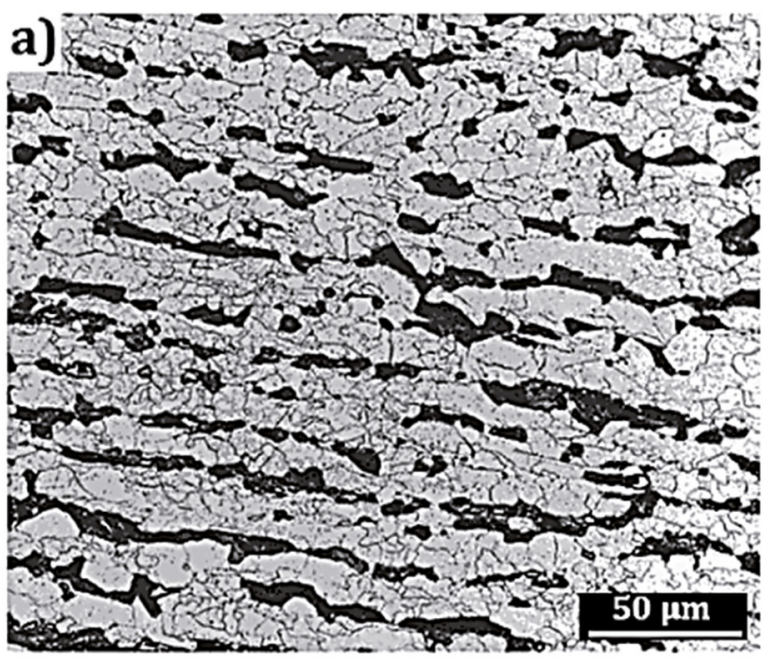

Figure 1: (a) SEM micrograph, (b) ODF at $\varphi_{2}=45^{\circ}$ of initial material.
$1 \mu \mathrm{m}$ diamond paste. Then, samples were etched with a $2 \%$ Nital solution to determine the microstructure using optical microscope (Zeiss Axio Imager.M2m) and scanning electron microscope (FEI Quanta 450 FEG SEM). The Vickers microhardness was also measured on all samples in the central regions, which were subjected to lower thermally induced deformation and lower thermal shocks. Each hardness result was determined from an average of ten measurements with a 49.03 $\mathrm{N}$ indentation load (HV5) in the mentioned areas. In addition, tensile tests were performed based on the ASTM E8M-13a standard on samples with a gauge length of 50 $\mathrm{mm}$ and overall length of $200 \mathrm{~mm}$ under a strain rate of 2 $\times 10^{-2} \mathrm{~s}^{-1}$ at room temperature.

The electron backscattered diffraction (EBSD) measurements were conducted using an Oxford Channel 5-EBSD system installed in a field emission SEM (FEI Quanta 450 FEG). These analyses were carried out in areas of $100 \times 100 \mu \mathrm{m}$ using a step size of $0.5 \mu \mathrm{m}$. In the EBSD measurements, the grain orientation, grain boundary distributions, misorientation, and Taylor factor were analysed using Oxford Instruments Channel 5 and the MTEX free and open source software toolbox. In this study, boundary misorientation was defined as follows: point-to-point misorientation of less than $15^{\circ}$ was considered as a $\mathrm{LAB}$ and point-to-point misorientation greater than $15^{\circ}$ was considered as an HAB. Also, the deformation texture was simulated through Taylor type models using HKL Technology Channel 5.

\section{Results and discussion}

\subsection{Microstructural investigation}

The optical and scanning electron micrographs of specimens are shown in Figures 2 and 3, respectively. Ferrite was the most common constituent in the as-rolled structure, with a limited amount of carbon in the iron (less

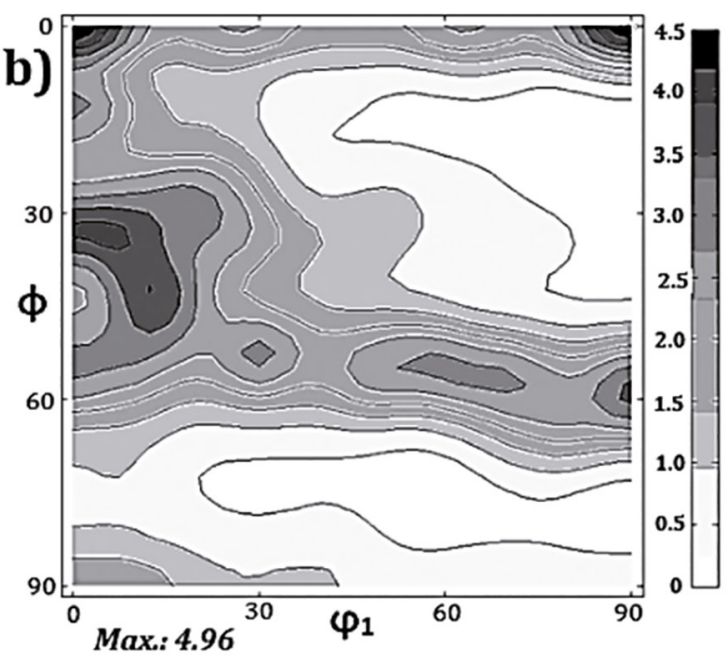


Table 1: The post-heat treatment processing underwent by each one of these specimens.

\begin{tabular}{lccc}
\hline Sample & Total thickness red. (\%) & Cooling Condition & Post-heat treatment \\
\hline AC & & Air cooling & - \\
ACN & 67.5 & Air cooling & Normalizing at $850^{\circ} \mathrm{C}$ for $3600 \mathrm{sec}$. \\
WQ350 & & Water quenching & Tempering at $350^{\circ} \mathrm{C}$ for $3600 \mathrm{sec}$. \\
WQ700 & & Water quenching & Tempering at $700^{\circ} \mathrm{C}$ for $3600 \mathrm{sec}$. \\
\hline
\end{tabular}
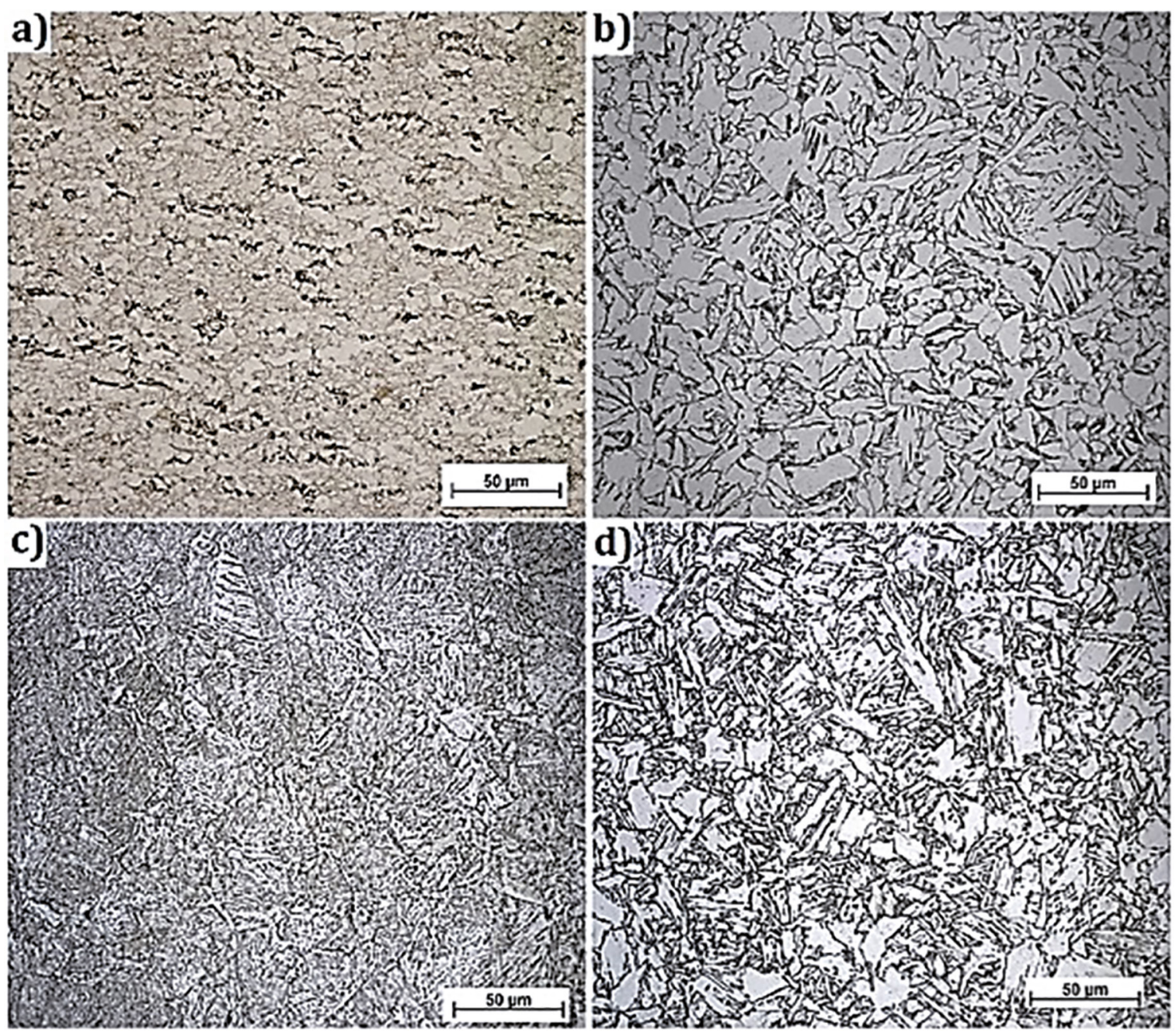

Figure 2: Optical micrograph of (a) AC, (b) ACN, (c) WQ350 and (d) WQ700 samples.

than $0.005 \%$ at room temperature), as shown in Figure $2 \mathrm{a}$. The excess carbon is rejected from the ferrite to the adjacent austenite. On cooling this enriched austenite, cementite (iron carbide) particles, ferrite, and pearlite form as microconstituents, as shown in Figure 3a. In the normalized sample, ferrite with different morphologies such as elongated, polygonal, andneedles type, called acicular ferrite, which mostly nucleated at the grain boundaries, appeared (Figure 3b). The micrographs show that the hot rolling enhanced the recrystallization of grains or formed pancaked austenite grains that produced more nucleation sites for ferrite nucleation. Both mechanisms led to grain refinement from $8 \mu \mathrm{m}$ (in as-received material) to $6 \mu \mathrm{m}$ during hot rolling. However, normalization at $850{ }^{\circ} \mathrm{C}$ increased the ferrite grain size to $16 \mu \mathrm{m}$.

The immediate quenching after rolling at elevated temperature formed a hard and brittle martensitic structure due to the large amount of internal strain from supersaturation of carbon atoms in the lattice ${ }^{16}$. It is notable that in API steel with low carbon content, carbon cannot occupy the octahedral positions in the body-centered cubic (BCC) lattice ${ }^{17}$. Thus, a $\mathrm{BCC}$ martensite structure results, which is softer and tougher than the ordinary body centred tetragonal (BCT) martensite. Therefore, tempering at two different temperatures was 

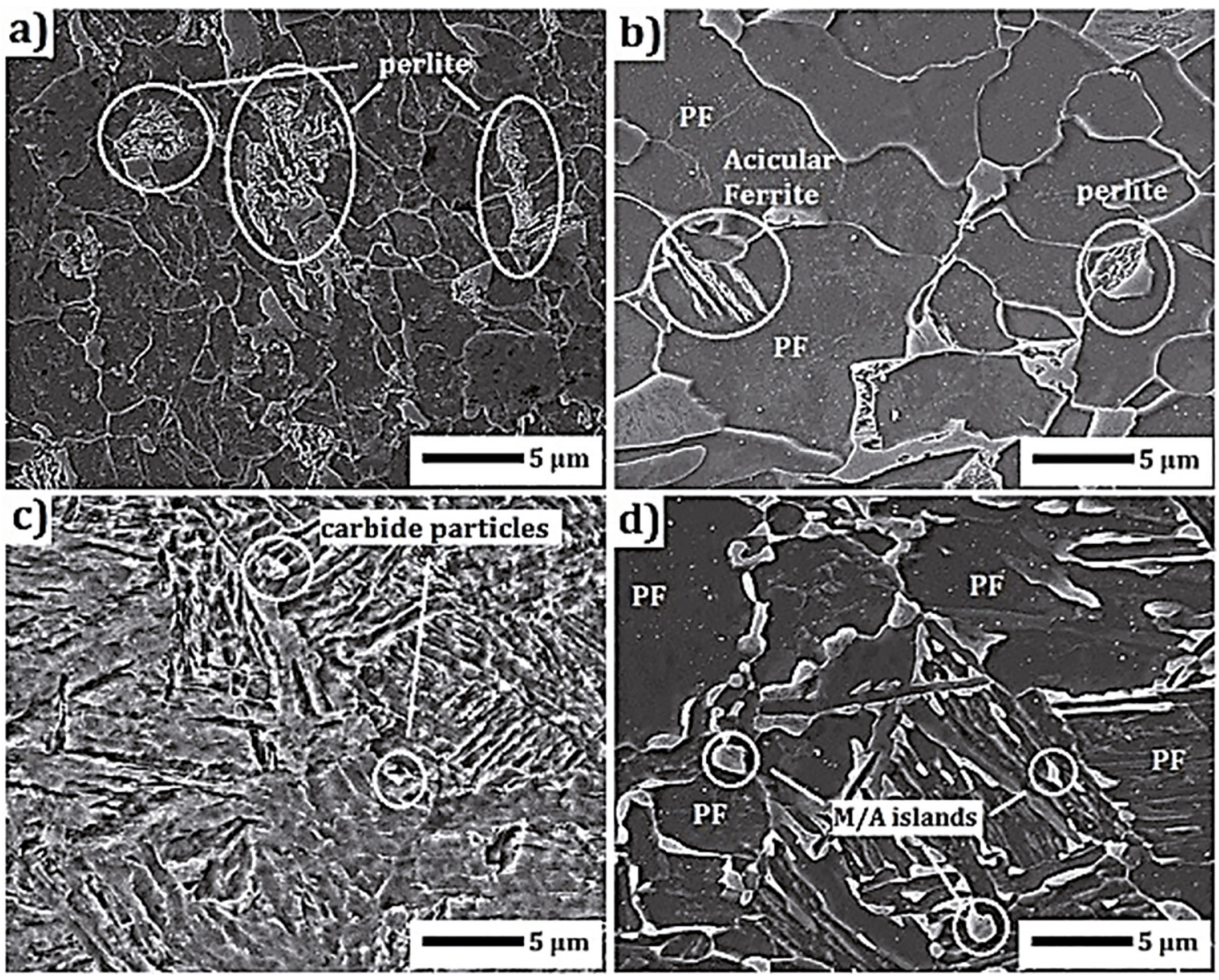

Figure 3: Scanning electron micrograph of (a) AC, (b) ACN, (c) WQ350 and (d) WQ700 samples.

carried out to regain the mechanical properties and ductility. Different morphologies of tempered martensite due to the tempering at 350 and $700{ }^{\circ} \mathrm{C}$ are shown in Figures 2 and 3 . Figures $2 \mathrm{c}$ and $3 \mathrm{c}$ show the lath martensite with dispersed carbide particles that are typical of the microstructure of low carbon steels. Also, it is expected that some other phases, such as bainite, pearlite, or retained austenite, can be found in this condition. Figures $2 \mathrm{~d}$ and $3 \mathrm{~d}$ illustrate the dual phases in the microstructure consisting of hard martensite-austenite constituents (M/A islands) dispersed in a soft ductile ferrite matrix after water quenching followed by tempering at a constant temperature of $700{ }^{\circ} \mathrm{C}$.

\subsection{Mechanical Properties}

API X70 pipeline steel for the designed purpose is required to meet the API 5L supplementary requirements. These requirements avoid any catastrophic failure of pipelines due to deformation as a result of ground movement and any other unexpected incidents. The minimum values of yield and ultimate tensile stress for X70 steel are 486 and 565 Mpa (70,000 and 82,000 psi), respectively. Also, according to the API specification, the ratio of yield to tensile stress (YS/TS) must not exceed 0.93 . The mechanical properties such as yield, ultimate tensile stress, yield to tensile stress (YS/TS) ratio, and elongation under different conditions obtained by tensile testing are shown in Figure 4 and listed in Table 2. The AC sample with refined ferrite microstructure

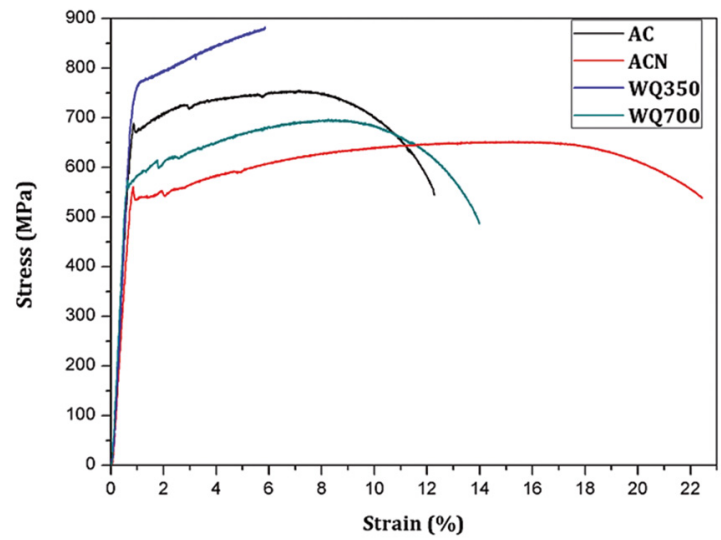

Figure 4: Engineering stress-strain curves of investigated samples. 
Table 2: The yield, ultimate tensile stress, yield to tensile stress (YS/TS) ratio, elongation and hardness of specimens

\begin{tabular}{lccccc}
\hline Sample & Yield Stress (Mpa) & Ultimate tensile Stress (Mpa) & YS/TS ratio & Tot. El. (\%) & Hardness (HV) \\
\hline AC & $686 \pm 5$ & $751 \pm 7$ & 0,91 & $12.4 \pm 1.5$ & $190 \pm 5$ \\
ACN & $536 \pm 8$ & $649 \pm 10$ & 0,82 & $21.8 \pm 1.8$ & $178 \pm 7$ \\
WQ350 & $780 \pm 8$ & $875 \pm 7$ & 0,89 & $5.5 \pm 0.5$ & $221 \pm 11$ \\
WQ700 & $574 \pm 4$ & $696 \pm 4$ & 0,82 & $14.2 \pm 1.6$ & $182 \pm 9$ \\
\hline
\end{tabular}

had an acceptable yield and ultimate strength. In the ACN sample, normalization led to significant grain growth. Thus, decreases in the yield and ultimate strength were obtained, in accordance with the Hall-Petch equation ${ }^{18,19}$. On the contrary, a significant increase in total elongation was observed in this sample. Thus, this sample successfully met the API specification. Further, the yield strength of the WQ350 sample was evaluated as the highest among the specimens because of the hard martensite structure. Consequently, the WQ350 sample could not meet the requirements, because of the very low elongation and brittle fracture mode. However, the tempering temperature of $700{ }^{\circ} \mathrm{C}$ led to a ferritic structure with relieved internal stress, combined with small hardened particles of M/A constituents. This microstructure leads to a significant improvement in the mechanical properties and meets the pipeline requirements.

The hardness measurements show that the refined ferrite microstructure in the AC sample increased the hardness from $165 \pm 5$ to $190 \pm 5 \mathrm{HV}$. Then, normalization decreased the hardness to $178 \pm 7 \mathrm{HV}$ because the residual stress was relieved by recovery and dynamic recrystallization, grain growth, and the development of uniform polygonal ferrite in the microstructure. Further, the WQ350 sample had the highest hardness value among all specimens due to the creation of a huge number of dislocations and crystallographic defects during water quenching and final brittle martensite even after tempering at $350{ }^{\circ} \mathrm{C}$. However, tempering at $700{ }^{\circ} \mathrm{C}$ reduced the hardness to $182 \pm 9 \mathrm{HV}$.

\subsection{Crystallographic orientation analysis}

In order to observe the changes of the microstructural parameters such as the crystallographic orientation, boundary distributions, and Taylor factor when the samples were subjected to hot rolling and various post heat treatments, EBSD measurements were carried out. The normal direction inverse pole figure (IPF) maps of specimens are presented in Figure 5. The inhomogeneity of the microstructure $-\mathrm{a}$ mixture of various ranges of fine and coarse grains in the microstructure of the sample subjected to hot rolling followed by air cooling (Figure 5a) - creates local stress concentration sites and leads to a decrease in the mechanical properties. Furthermore, the normalization at $850{ }^{\circ} \mathrm{C}$ enhanced grain growth (Figure $5 \mathrm{~b}$ ). Water quenching forms martensite with high dislocation density. Then, tempering at $350{ }^{\circ} \mathrm{C}$ could not relieve the induced stored energy, and as a consequence, a low Kikuchi pattern quality was detected by EBSD. Finally, tempering at $700{ }^{\circ} \mathrm{C}$ led to the development of a quasi-polygonal ferritic structure, and a good quality Kikuchi pattern was obtained due to the low stored energy because of dislocation annihilation.

In order to achieve a better understanding of the evolution of the crystallographic orientation during hot deformation and post heat treatments, the orientation distribution function (ODF) was calculated for individual IPF maps and is shown in Figure 6 . The $\{111\} / / \mathrm{ND}$ texture components, including the $(111)<211>,(111)[\overline{101}]$, and (112)[021] components, were characterized in the AC sample, which is common in hot-rolled low carbon steels (Figure 6a). Interestingly, normalization at $850^{\circ} \mathrm{C}$ significantly changed the orientation

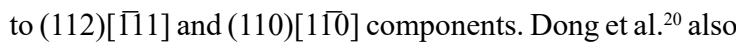
reported that the copper component (112)[111] identified in the ACN sample, as shown in Figure 6b, can enhance the mechanical properties. In this respect, the ferritic structure (i.e. polygonal and acicular ferrite) and the presence of the pearlite microconstituent associated with the copper component lead to a good combination of strength and elongation in this condition. Furthermore, non-diffusional martensitic transformation of austenite grains by water quenching led to the development of $(001)<110>$ rotated cube components with undesired cleavage (Figure 6c). In several studies ${ }^{21-23}$, the rotated cube components are reported to be responsible for the brittle cleavage fracture in $\mathrm{BCC}$ materials. Tempering at a constant temperature of $700^{\circ} \mathrm{C}$ led to the formation of $(111)<101>,(232)[1 \overline{45}]$, and $(001)<130>$ components, as shown in Figure 6d. Bhadeshia et al. ${ }^{24}$ showed that (111) [101] texture components are one of the crystallographic slip systems deformed by martensitic transformation which facilitate dislocation displacement and improve the mechanical properties. Moreover, Rollet ${ }^{25}$ also found that the (001)[130] texture tends to retard crack initiation and simultaneously improve the mechanical and electrical properties caused by internal stress due to substitutional and interstitial elements in the parent lattice. Therefore, our findings show the importance of the crystallographic texture for the mechanical behaviour.

Boundary distributions that can control the mechanical properties are strongly dependent on the crystallographic orientations and misorientation angles in individual grains ${ }^{26}$. In general, microstructures with high dislocation density and a large fraction of HABs are prone to early fracture, while LABs and special boundaries with good lattice 

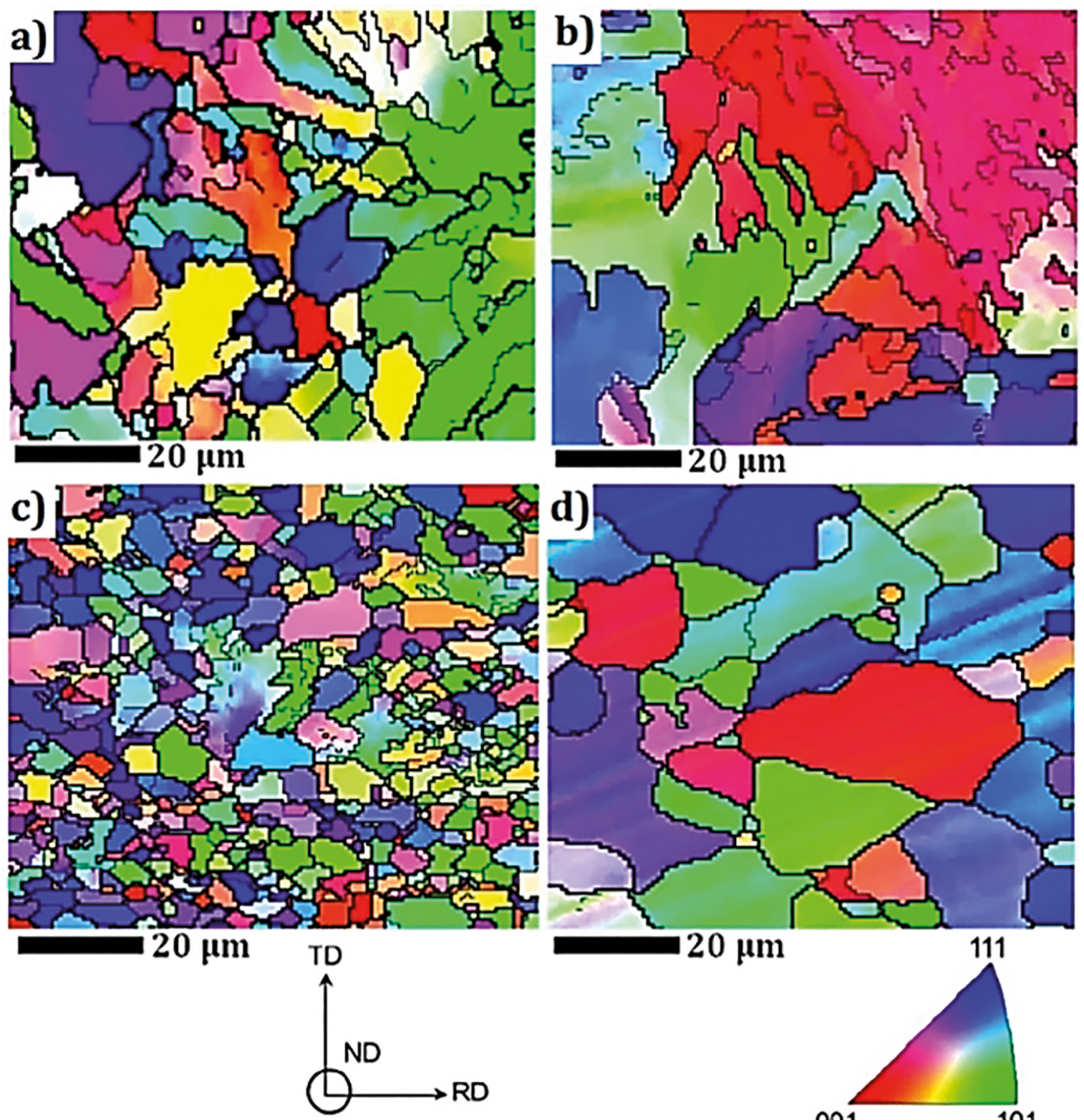

Figure 5: IPF maps of (a) AC, (b) ACN, (c) WQ350 and (d) WQ700 samples.

compliance are more resistant to yielding. The boundary distributions in the investigated samples are presented in Figure 7. A high fraction of LABs was characterized in the AC, ACN, and WQ700 samples. Jakobsen et al. ${ }^{27}$ reported that dislocations were trapped inside sub-grain boundaries by low-range dislocation movement, leading to increases in lattice distortion and local stress concentration and finally early fracture. In addition, the average misorientation angles $(\theta \mathrm{av})$ related to average crystallographic lattice incompliance were calculated and are noted in Figure 7. The maximum amount of $\theta$ av was obtained in the sample that was quenched and then tempered at $350{ }^{\circ} \mathrm{C}$, indicating that this sample had the highest instability and lattice distortion, resulting in low ductility during tensile loading. Conversely, the ACN and WQ700 samples had the lowest level of $\theta \mathrm{av}$, indicating enhancement of the mechanical properties.

Taylor factor analysis can predict the level of plastic deformation of individual grains based on the family of active slip systems. Taylor ${ }^{28}$ was the first to attempt to explain this discrepancy by tracking the behaviour of each crystal associated with neighbouring crystals and applied strain ${ }^{29}$. Regarding the slip systems of each crystal and applied loading direction, grains are categorized into three groups. In the first group, the grains' slip planes are already aligned in the loading direction, which means that slip can easily occur when critical resolved shear stress is achieved, as indicated in 

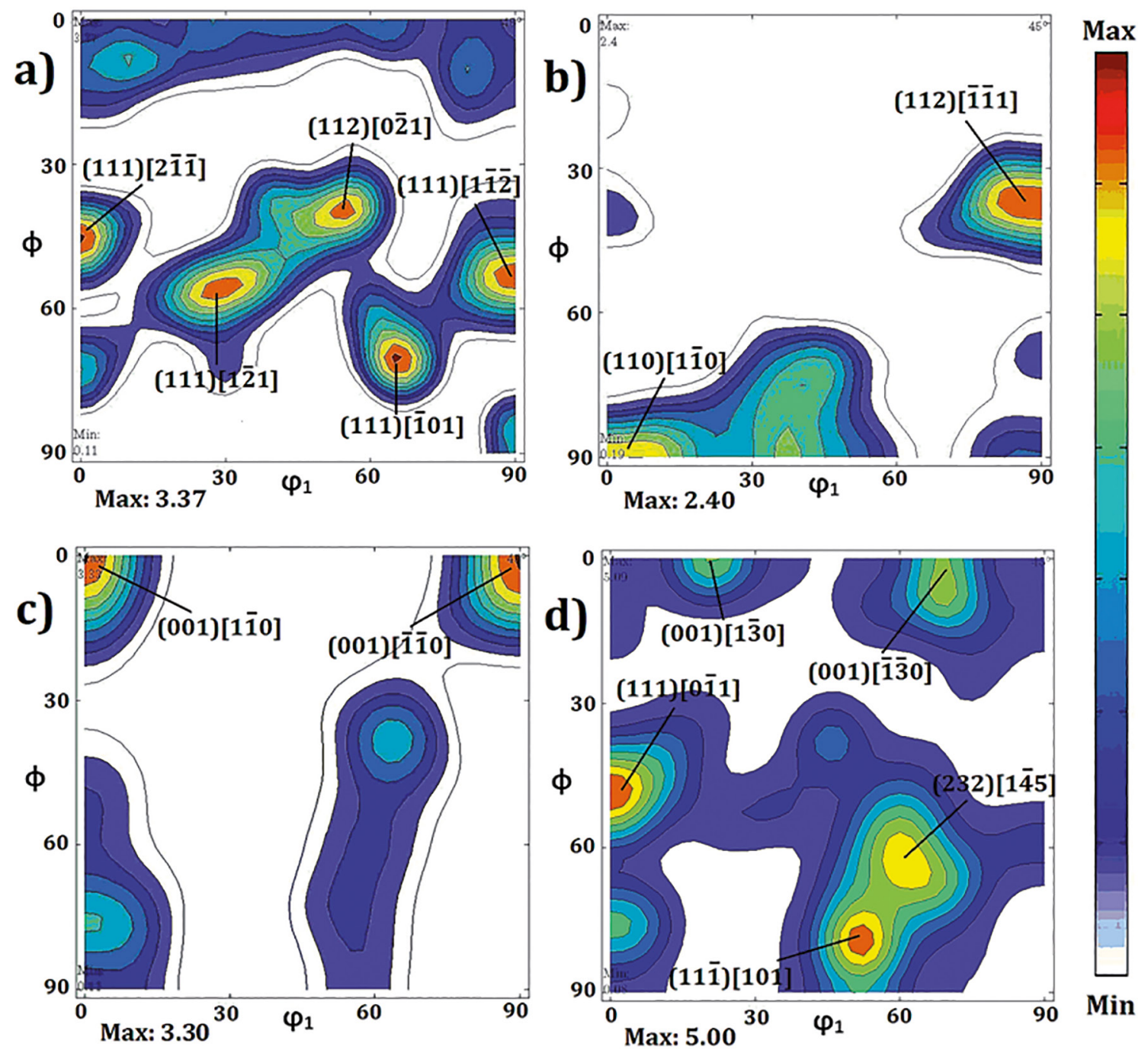

Figure 6: ODF of sample at $\varphi_{2}=45^{\circ}$ of (a) AC, (b) ACN, (c) WQ350 and (d) WQ700 samples.

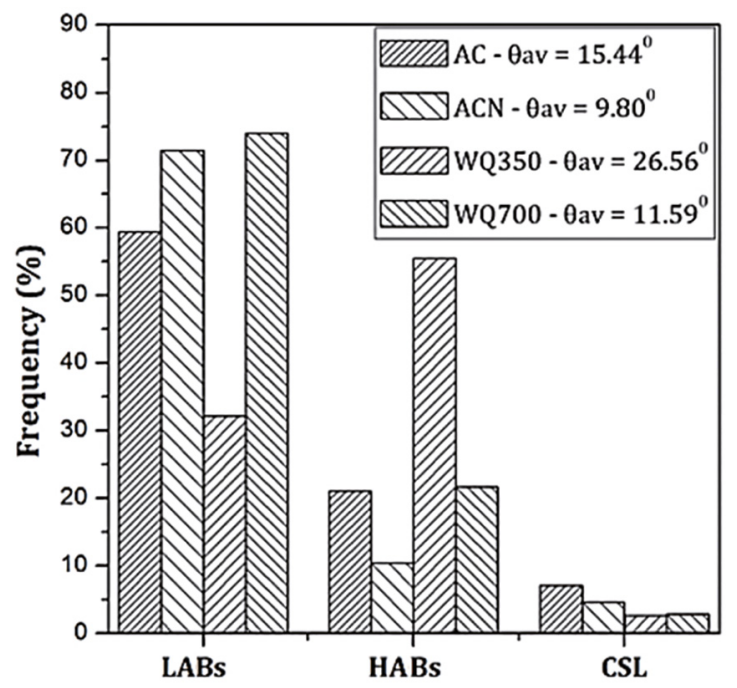

Figure 7: Distribution of boundary characteristics in investigated specimens. blue colour on Taylor factor maps. In the second group, the grains are rotated in an ideal direction to give an appropriate slip plane position where plastic deformation can occur, as indicated in yellow and light green. Finally, the third group is formed by the grains that cannot rotate to bring appropriate slip planes for the occurrence of plastic deformation. These grains are called hard grains or hard orientations and are indicated in red on the Taylor factor maps ${ }^{30}$. Therefore, low Taylor factors lead to easy deformation, while high Taylor factors predict higher resistance to deformation. Figure 8 shows the Taylor factor maps calculated via the Taylor model under the boundary conditions using EBSD data.

The activation of slip systems depends on the crystallographic orientation and local stress differences close to the grain boundaries between adjacent grains ${ }^{31}$. The Taylor factor was calculated using the family of active slip systems for BCC metals $\{110\}<111>$ and the plane strain deformation ${ }^{32}$, and the Taylor factor maps of all investigated samples are presented 

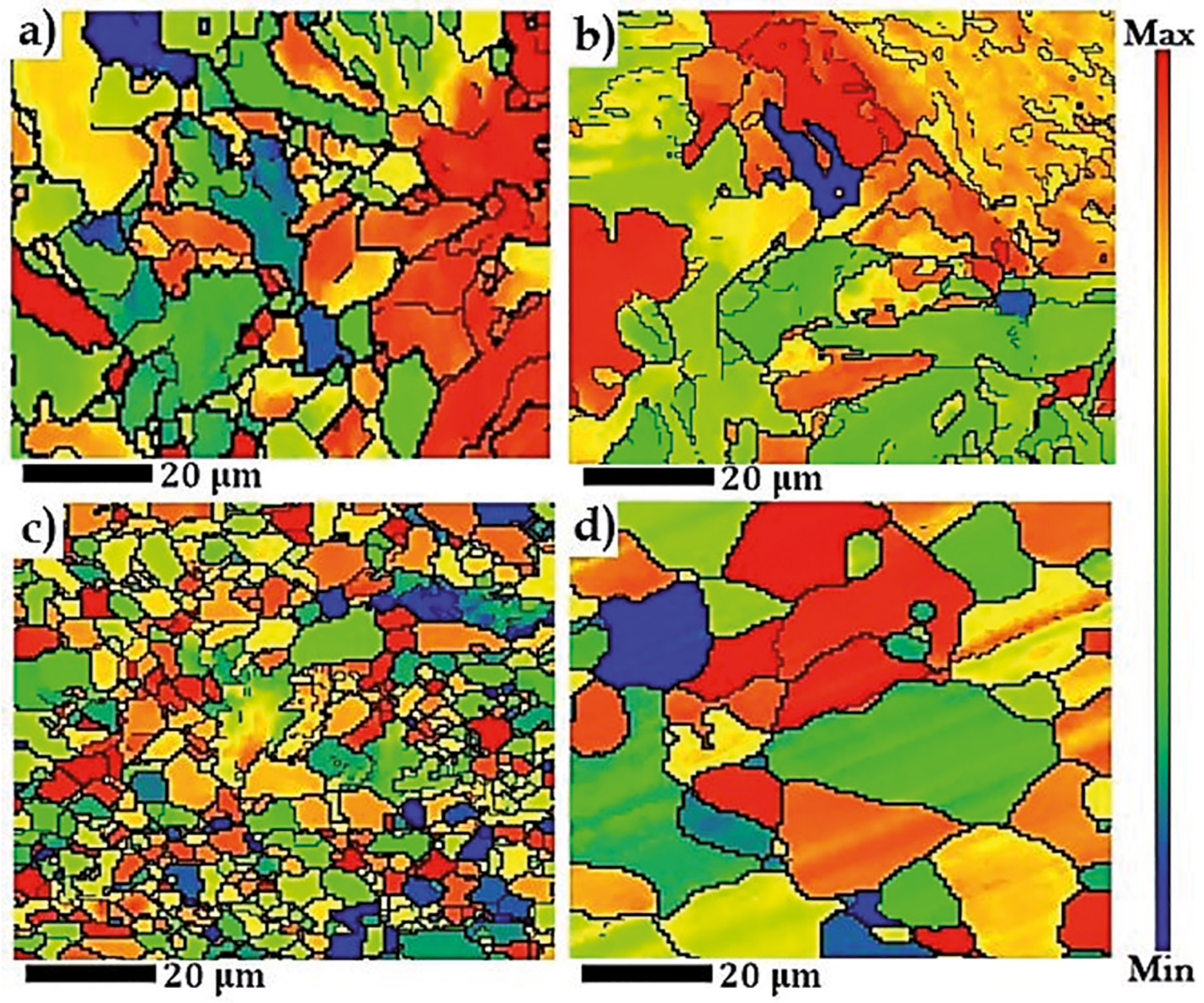

Figure 8: Taylor Factor maps of (a) AC, (b) ACN, (c) WQ350 and (d) WQ700 samples.

in Figure 9. The AC and WQ350 samples showed the highest Taylor factors; consequently, more energy will be required to start deformation. The grains with high stored energy have more resistance to yielding. In other words, grain boundary sliding is restricted in neighbouring grains with high local stress differences due to crystallographic orientation and/or induced by primary strain, and thus crack formation is expected in these regions. However, the relatively easier deformation due to the low Taylor factor in the ACN and WQ700 samples due to dislocation displacement led to improvements in the mechanical properties, as shown in Figure 4.

From the results, it could be concluded that the engineering of crystallographic texture and microstructure by rolling in the recrystallization temperature region associated with a post-heat treatment play a significant role in the improvement of mechanical properties. Among all conditions, the sample subjected to hotrolling followed by quenching and tempering at $700^{\circ} \mathrm{C}$ exhibited excellent mechanical properties because of the formation of the recrystallized ferrite microstructure and tempered martensite with martensite-austenite constituent dispersion, respectively. Moreover, developing the (112)[111] and (111)[101] texture components enhanced mechanical properties.

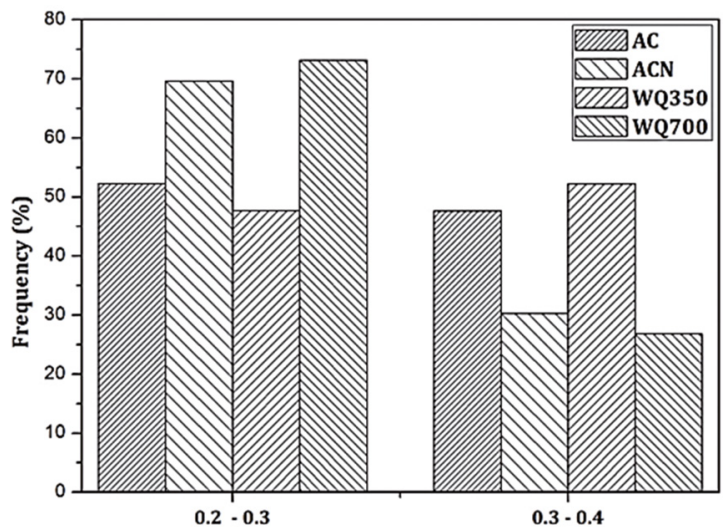

Figure 9: The variation of Taylor factor value in specimens

\section{Conclusions}

A rolling schedule based on engineering of crystallographic texture in the recrystallization temperature region associated with a post heat treatment of API X70 pipeline steel was proposed. In addition, the effects of microstructural parameters such as crystallographic orientation, boundary distributions, 
and Taylor factor were studied and the following conclusions can be drawn:

- $\quad$ The normalized hot-rolled sample and the sample subjected to hot-rolling followed by quenching and tempering at $700{ }^{\circ} \mathrm{C}$ exhibited excellent mechanical properties because of the formation of the recrystallized ferrite microstructure and tempered martensite with martensite-austenite constituent dispersion, respectively.

- The mechanical properties decreased drastically in the WQ350 sample due to the formation of brittle martensite and the presence of the cleavage $(001)<110>$ rotated cube components.

- $\quad$ The development of the (112)[1] and (111)[10] texture components in the ACN and WQ700 samples improved the mechanical properties.

- The AC and WQ350 samples with high Taylor factors are more prone to fracture. The ACN and WQ700 samples with low Taylor factors are able to provide enough slip systems to facilitate dislocation motion, leading to increased ductility.

\section{Acknowledgements}

The authors acknowledge the Brazilian research agencies; $\mathrm{CNPq}$, the research board of the Universidade Federal do Ceará for the financial support and Laboratório de Caracterização de Materiais (LACAM) and Central Analytical (CT-INFRA/MCTI-SISNAD) for provision of research facilities of this work.

\section{References}

1. Pedrosa IRV, Castro RS, Yadava YP, Ferreira RAS. Study of phase transformations In API 5L X80 Steel in order to increase its fracture toughness. Materials Research. 2013;16(2):489-496.

2. Ferreira LS, Graf K, Scheid A. Microstructure and Properties of Nickel-based C276 Alloy Coatings by PTA on AISI 316L and API 5L X70 Steel Substrates. Materials Research. 2015;18(1):212-221.

3. Biletsky SM. Design Technology, Production and Principal Features of Multilayer Pipes for Trunk Gas Pipelines. In: Zhou Y. Pipeline and Energy Plant Piping, Design and Technology. Oxford: Pergamon; 1980. p. 43-49.

4. Atkins AG, Martins PAF. Metal Forming: Formability. Reference Module in Materials Science and Materials Engineering. 2016.

5. Cui J, Sun G, Xu J, Huang X, Li G. A method to evaluate the formability of high-strength steel in hot stamping. Materials \& Design. 2015;77:95-109.

6. Koo JY, Thomas G. Metallurgical factors controlling impact properties of two phase steels. Scripta Metallurgica. 1979;13(12):1141-1145.

7. Randle V, Engler O. Introduction to Texture Analysis: Macrotexture, Microtexture and Orientation Mapping. Boca Raton: CRC Press; 2009. p. 118-225.
8. Masoumi M, Herculano LFG, Abreu HFG. Study of texture and microstructure evaluation of steel API 5L X70 under various thermomechanical cycles. Materials Science and Engineering: A. 2015;639:550-558.

9. Blondé R, Jimenez-Melero E, Zhao L, Wright JP, Brück E, van der Zwaag S, et al. High-energy X-ray diffraction study on the temperature-dependent mechanical stability of retained austenite in low-alloyed TRIP steels. Acta Materialia. 2012;60:565-577.

10. Nafisi S, Arafin MA, Collins L, Szpunar J. Texture and mechanical properties of API X100 steel manufactured under various thermomechanical cycles. Materials Science and Engineering. A. 2012;531:2-11.

11. Yang $\mathrm{XL}, \mathrm{Xu}$ YB, Tan XD, Wu D. Relationships among crystallographic texture, fracture behavior and Charpy impact toughness in API X100 pipeline steel. Materials Science and Engineering: A. 2015;641:96-106.

12. Xie H, Du LX, Hu J, Sun GS, Wu HY, Misra RDK. Effect of thermo-mechanical cycling on the microstructure and toughness in the weld CGHAZ of a novel high strength low carbon steel. Materials Science and Engineering: A. 2015;639:482-488.

13. Yang Y, Shi L, Xu Z, Lu H, Chen X, Wang X. Fracture toughness of the materials in welded joint of $\mathrm{X} 80$ pipeline steel. Engineering Fracture Mechanics. 2015;148:337-349.

14. American Petroleum Institute. Specification for Line Pipe. API specification $5 L .42^{\text {nd }}$ ed. Washington: American Petroleum Institute; 2000.

15. Palmiere EJ, Garcia CI, DeArdo AJ. Influence of Processing Conditions and Alloy Chemistry on the Static Recrystallisation of Microalloyed Austenite. Materials Science Forum. 1998;284286:151-158

16. Kelly PM. The martensite transformation in steels with low stacking fault energy. Acta Metallurgica. 1965;13(6):635-646.

17. Viswanathan UK, Dey GK, Asundi MK. Precipitation Hardening in 350 Grade Maraging Steel. Metallurgical Transactions A. 1993;24(11):2429-2442.

18. Hall EO. The Deformation and Ageing of Mild Steel: III Discussion of Results. Proceedings of the Physical Society. Section B. 1951;64(9):747-753.

19. Petch NJ. The Cleavage Strength of Polycrystals. Journal of Iron and Steel Research. 1953;174:25-28.

20. ZD Li, Sun XJ, Cao WQ, Yong QL, Yang ZG, Dong H, et al. Ausforming effects on anisotropy of mechanical properties in HSLA martensitic steel. Science China Technological Sciences. 2012:55(7):1806-1813.

21. Siqueira RP, Sandim HRZ, Oliveira TR, Raabe D. Composition and orientation effects on the final recrystallization texture of coarse-grained $\mathrm{Nb}$-containing AISI 430 ferritic stainless steels. Materials Science and Engineering A. 2011;528(9):3513-3519.

22. Botelho RA, Diniz SB, Cunha MA, Brandão LP. Properties of NGO 3\% Silicon Steel Asymmetrically Cold Rolled. Materials Research. 2015;18(2):143-147.

23. Ghosh A, Kundu S, Chakrabarti D. Effect of crystallographic texture on the cleavage fracture mechanism and effective grain size of ferritic steel. Scripta Materialia. 2014;81:8-11. 
24. Abreu HFG, Silva MJG, Herculano LGF, Bhadeshia H. Texture analysis of deformation induced martensite in an AISI 301L stainless steel: microtexture and macrotexture aspects. Materials Research. 2009;12(3):291-297.

25. Rollett AD, ed. Materials Processing and Texture: Ceramic Transactions, Volume 200. New Jersey: Wiley; 2008. p. 214-226.

26. Humphreys FJ, Hatherly M. Grain growth following recrystallization. In: Humphreys FJ, Hatherly M. Recrystallization and Related Annealing Phenomena. Oxford: Pergamon; 1995. p. 281-325.

27. Jakobsen B, Poulsen HF, Lienert U, Almer J, Shastri SD, Sørensen $\mathrm{HO}$, et al. Formation and Subdivision of Deformation Structures During Plastic Deformation. Science. 2013;312(5775):889-892.

28. Taylor GL. Plastic strain in metals. Journal of the Institute of Metals. 1938;62:307-324.
29. Shen JH, Li YL, Wei Q. Statistic derivation of Taylor factors for polycrystalline metals with application to pure magnesium. Materials Science and Engineering: A. 2013;582:270-275.

30. Kocks UF, Mecking H. Physics and phenomenology of strain hardening: the FCC case. Progress in Materials Science. 2003;48(3):171-273.

31. Fukuya K, Nishioka H, Fujii K, Miura T, Torimaru T. An EBSD examination of SUS316 stainless steel irradiated to 73 dpa and deformed at $593 \mathrm{~K}$. Journal of Nuclear Materials. 2011;417(1-3):958-962.

32. Delannay L, Jacques PJ, Kalidindi SR. Finite element modeling of crystal plasticity with grains shaped as truncated octahedrons. International Journal of Plasticity. 2006;22(10):1879-1898. 